\title{
The contribution of zooplankton faecal pellets to deep-carbon transport in the Scotia Sea (Southern Ocean)
}

\author{
C. Manno, G. Stowasser, P. Enderlein, S. Fielding, and G. A. Tarling \\ British Antarctic Survey, Natural Environmental Research Council, High Cross, Madingley Road, Cambridge, CB3 0ET, UK \\ Correspondence to: C. Manno (clanno@bas.ac.uk)
}

Received: 17 September 2014 - Published in Biogeosciences Discuss.: 26 November 2014

Revised: 11 February 2015 - Accepted: 17 February 2014 - Published: 25 March 2015

\begin{abstract}
The northern Scotia Sea contains the largest seasonal uptake of atmospheric carbon dioxide yet measured in the Southern Ocean. This study examines one of the main routes by which this carbon fluxes to the deep ocean: through the production of faecal pellets (FPs) by the zooplankton community. Deep sediment traps were deployed at two sites with contrasting ocean productivity regimes (P3, naturally iron-fertilized, and P2, iron-limited) within the same water mass. The magnitude and seasonal pattern of particulate organic carbon (POC) and FPs in the traps was markedly different between the two sites. Maximum fluxes at P3 (22.91 $\left.\mathrm{mg} \mathrm{C} \mathrm{m}^{-2} \mathrm{~d}^{-1} ; 2534 \mathrm{FP} \mathrm{m}^{-2} \mathrm{~d}^{-1}\right)$ were 1 order of magnitude higher than at P2 $\left(4.01 \mathrm{mg} \mathrm{C} \mathrm{m}^{-2} \mathrm{~d}^{-1}\right.$; $915 \mathrm{FP} \mathrm{m}^{-2} \mathrm{~d}^{-1}$ ), with flux at P3 exhibiting a double seasonal peak, compared to a single flatter peak at P2. The maximum contribution of FP carbon to the total amount of POC was twice as high at P3 (91\%) compared to P2 (40\%). The dominant FP category at P3 varied between round, ovoidal, cylindrical and tabular over the course of the year, while, at P2, ovoidal FPs were consistently dominant, always making up more than $60 \%$ of the FP assemblage. There was also a difference in the FP state between the two sites, with FPs being relatively intact at $\mathrm{P} 3$, while FPs were often fragmented with broken peritrophic membranes at P2. The exception was ovoidal FPs, which were relatively intact at both sites. Our observations suggest that there was a community shift from a herbivorous to an omnivorous diet from spring through to autumn at P3, while detritivores had a higher relative importance over the year at P2. Furthermore, the flux was mainly a product of the vertically migrating zooplankton community at P3, while the FP flux was more likely to be generated by deeper-dwelling zooplankton feeding on recycled material at $\mathrm{P} 2$. The results demonstrate that the feeding behaviour and
\end{abstract}

vertical distribution of the zooplankton community plays a critical role in controlling the magnitude of carbon export to the deep ocean in this region.

\section{Introduction}

The largest export by the biological carbon pump is via passive sinking of particulate organic carbon (POC), which is comprised of phytoplankton aggregates, detritus, living and dead cells, moults, and zooplankton faecal products (Fowler and Knauer, 1986). The importance of faecal pellets (FPs) for the export of organic material from the euphotic zone into deeper waters has been widely recognised (Bathmann and Liebezeit, 1986; Fowler et al., 1991; Wexels Riser et al., 2002). Zooplankton FPs are a ubiquitous component of the oceanic particle flux and are an important nutrient source for deep-water ecosystems (Turner, 2002). Small pellets generated by microzooplankton and small copepods have slow sinking rates and are likely to be remineralized by degradation and recycling processes during sinking (Dagg et al., 2003). By contrast, large zooplanktons produce larger FPs that sink more rapidly and are less likely to be remineralized (Lampitt et al., 1990; Wassmann, 1998). They therefore provide a major conduit for the transfer of organic matter to the deep ocean (Komar et al., 1981; Bruland and Silver, 1981). Alongside passive sinking, the transport of POC is facilitated through active transport by mesopelagic zooplankton that vertically migrate to the surface at night to feed and then egest FPs in the deeper ocean during the day (Atkinson et al., 1996; Kobari et al., 2008)

The Southern Ocean accounts for almost $20 \%$ of the global ocean $\mathrm{CO}_{2}$ uptake, principally due to $\mathrm{CO}_{2}$ fixation 
by phytoplankton the and successive downward particle flux of biogenic carbon (Toggweiler et al., 2003). The faeces of zooplankton represent an important component of biogenic flux in this region, with respect to both organic and siliceous materials (Fischer et al., 1988; Wefer et al., 1998), and can contribute up to $100 \%$ of the organic carbon flux (Accornero et al., 2003; Schmidt et al., 2011). Productivity over much of the Southern Ocean is limited by the lack of iron, an essential micronutrient for photosynthesis, resulting in there being an excess of macronutrients but low levels of chlorophyll (Martin et al., 1994). However, hotspots of productivity arise where iron becomes available; the region downstream of South Georgia is a notable case of this, with an extensive bloom supported until late summer by macronutrients and iron resupplied from the shelf edge, shelf-sediment interactions and vertical mixing of deep waters (Korb et al., 2008). Mesozooplankton biomass in this region can exceed the Southern Ocean average by a factor of 6 (Ward et al., 1995; Atkinson et al., 1996; Pakhomov et al., 1997), and there are large concentrations of Antarctic krill as well as high densities of marine- and land-based predators (Atkinson et al., 2001). This region has been estimated to have the largest seasonal uptake of atmospheric carbon dioxide yet measured in the Southern Ocean (Schlitzer, 2002; Baer Jones et al., 2012). Such Fe-fertilised regions of the Southern Ocean are also known to exhibit enhanced carbon export to the deep ocean (Pollard et al., 2009; Blain et al., 2007). Nevertheless, the magnitude of deep-carbon export around South Georgia, as well as the contribution of zooplankton FPs to the carbon flux, is still unknown.

Here, we describe a 3-year-long series of POC and faecalpellet fluxes, as measured by deep moored sediment traps located at two sites close to South Georgia. These sites were deliberately chosen to have contrasting productivity regimes (Korb et al., 2012) within the same water mass, with one site being naturally iron-fertilised (P3) and the other relatively iron-limited (P2). The aim of this work was to investigate the seasonal and regional change in the deep-carbon flux with a particular focus on the role of FPs in regulating the magnitude of carbon export in these two regions. We quantify zooplankton FP fluxes as well as their contribution to the overall POC flux. The relationship between different zooplankton feeding strategies and FP export is also considered.

\section{Methods}

Bottom-tethered moorings were repeatedly deployed at two sites (P2 and P3) for periods of approximately 12 months between February 2008 and April 2011. P2 was located at a site that was oceanographically upstream of South Georgia $\left(55^{\circ} 11.99 \mathrm{~S}, 41^{\circ} 07.42 \mathrm{~W}\right)$, while P3 was downstream $\left(52^{\circ} 43.40 \mathrm{~S}, 40^{\circ} 08.83 \mathrm{~W}\right)$ (Fig. 1). Each sediment trap (McLane Parflux sediment traps, $0.5 \mathrm{~m}^{2}$ surface collecting area; McLane Labs, Falmouth, MA, USA) carried 21

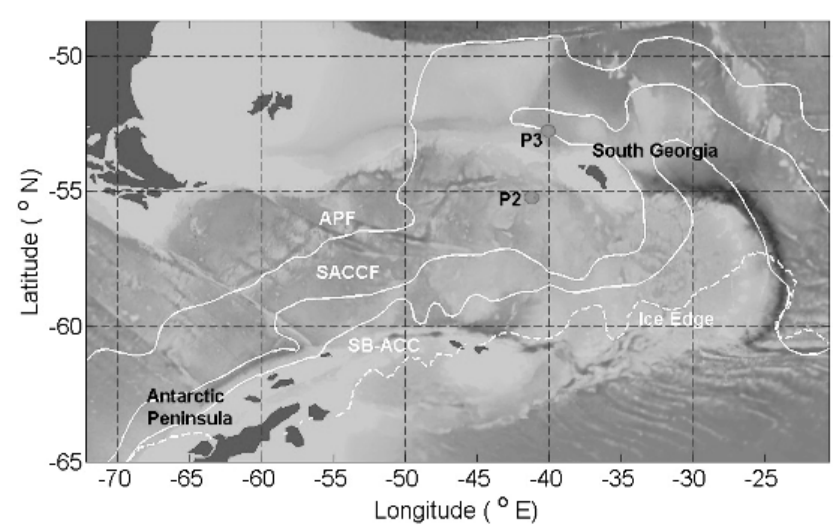

Figure 1. Map of study area in the Southern Ocean showing the locations of P3 and P2, APF stands for the Antarctic Polar Front, SACCF for Southern Antarctic Circumpolar Current Front and SBACC Southern Boundary of Antarctic Cirumpolar Current.

receiving cups and was fitted with a plastic baffle mounted in the opening, to prevent the entrance of large organisms. Prior to deployment, the receiving cups were filled with $\mathrm{NaCl}$ buffered $\mathrm{HgCl} 2$ seawater solution to arrest biological degradation during sample collection. Traps were deployed at a depth of $1500 \mathrm{~m}(\mathrm{P} 2$, water depth $3200 \mathrm{~m})$ and $2000 \mathrm{~m}$ (P3, water depth $3800 \mathrm{~m}$ ), and the sample carousel was programmed to rotate at intervals of 15 days in austral summer and 30 days in austral winter. The sample cup for February 2008 was not present on recovery. The period between December 2008 and February 2009 was missed due to bad weather delaying deployment. Note that, since mean current velocities were $<10 \mathrm{~cm} \mathrm{~s}^{-1}$ (Whitehouse et al., 2012) at both sites, we assume that lateral advection of material can be neglected.

\subsection{Trap sample processing and analyses}

Once in the laboratory, the supernatant of each cup was removed by pipette and its $\mathrm{pH}$ was measured in order to check for possible carbonate dissolution. Prior to splitting, "swimmers", i.e. zooplanktonic organisms that can enter the receiving cups while alive, were carefully removed: samples were first wet-sieved through a $1 \mathrm{~mm}$ nylon mesh and the remaining swimmers were hand-picked under a dissecting microscope. Large aggregates, fragments of moults and empty tests retained by the mesh were returned to the sample. Each sample was then divided into a series of replicate fractions for subsequent analysis using a McLane rotary sample splitter (McLane Labs, Falmouth, MA, USA). Replicate fractions were vacuum filtered through preweighed and precombusted $\left(450^{\circ} \mathrm{C}\right.$ for $4 \mathrm{~h}$ ) Whatman $\mathrm{GF} / \mathrm{F}$ filters for organic carbon (POC) analyses. Filters were then desalted by short washing with distilled water and dried at $60^{\circ} \mathrm{C}$. POC was measured by combustion in an elemental analyser (CHN); for POC determination, filters were previously treated with $2 \mathrm{~N} \mathrm{H}_{3} \mathrm{PO}_{4}$ and 
1N HCl. POC flux was expressed in $\mathrm{mg} \mathrm{m}^{-2} \mathrm{~d}^{-1}$, estimated by dividing the total mass per sample by the time interval and the trap collection area.

FPs were counted and classified with respect to their morphology, using a combination of light microscopy and scanning electron microscopy (SEM). Pellets were visually categorized by shape into five categories (ovoid, round, cylindrical, tabular and ellipsoidal; Fig. 2a-e). Following the literature cylindrical pellets could be attributed to euphausiids and large calanoid copepods (Gonzalez, 1992) and tabular pellets to salps (Accornero et al., 2003). Ellipsoidal faeces have also been described as copepod pellets but were mainly associated with larvaceans (Gorsky and Fenaux, 1998; Gonzalez and Smetacek, 1994). And while ovoid pellets could be produced by various groups including pteropods, chaetognaths, and cyclopoids and other small copepods (Manno et al., 2010; Gonzalez, 1992; Yoon et al., 2001), spherical pellets are attributed to small copepods and crustacean nauplii but also to amphipods (Gonzalez, 1992; Yoon et al., 2001). The dimensions of the first $60-100$ pellets of each morphological type observed for each sample were measured (length and width) using an ocular micrometer, from which pellet volume was calculated by the geometrical formulas associated with the FP shapes (i.e sphere, cylinder, ovoid) (Gonzales et al., 2000). Note that, due to the fragile nature of salp FP, this FP category was removed from all of the samples before splitting. Further identification of the content of FP types was carried out on subsamples using SEM. To semi-quantify the variability in FP contents and the state of preservation, a total of 60 FPs for each location was classified in terms of intact diatoms, fragmented diatoms and reworked material contents.

The FP carbon content of each FP category was estimated using an elemental (CHN) analyser, for which between 100 and 200 FPs from each category type were prepared. The exception was for the tabular type, for which only around 50 were prepared due to their rarity in samples. These categories were further subdivided into two periods: late spring-early autumn (October to April) and late autumn to the end of winter (May to September). The combination of these measurements with the FP volume estimates (detailed above) allowed us to determine a season-specific FP carbon (FPC) content, expressed as $\mathrm{mg} \mathrm{C} \mathrm{mm}^{-3}$ for each FP type. Note that faecal "fluff" (partially degraded FPs) was difficult to quantify, so our estimate of the importance of FPC to total flux is likely to be an underestimate.

Attempts were made to fit regressions to the relationship between total POC and either the total number of FPs (FPn) or the percentage of the total POC flux made up of FPC (\%FPC) for each station. Least-squares regression fitting was carried out using SIGMAPLOT 12.5 (SYSTAT Software 2011), in which a range of functions were used (linear, quadratic, power) to derive the best fit for the minimum number of parameters. A regression was only considered further if it achieved a significance value of $P<0.05$.
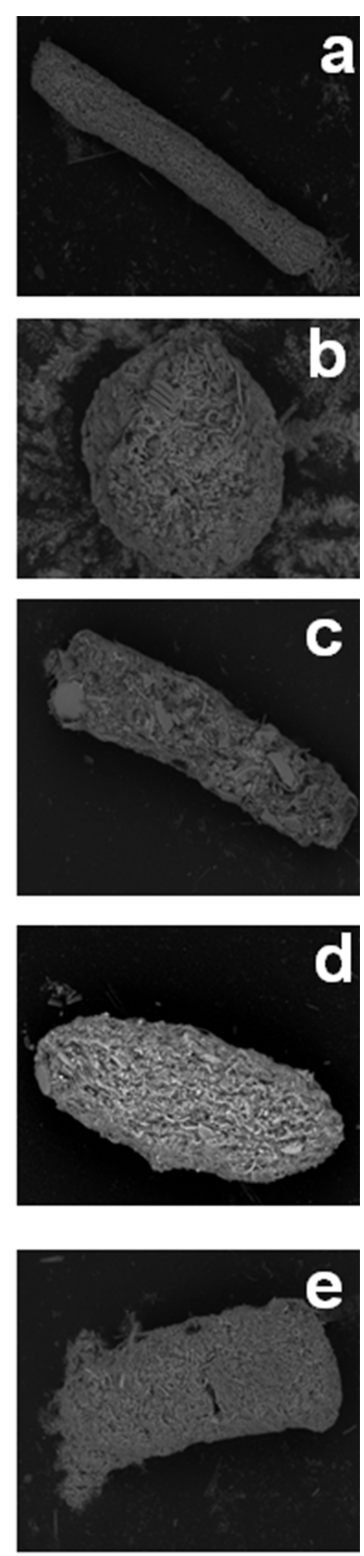

Figure 2. Scanning electron micrographs of the different FP types collected in the sediment traps: (a) cylindrical, (b) round, (c) ellipsoidal, (d) ovoid, (e) tabular.

One-way ANOVA tests were performed to determine whether there were any significant differences between seasons and sites with regard to the percentage of the total POC flux made up of FPC (\%FPC). All the data were checked for normality and variance homogeneity (Levene's test) before a Tukey's honest significant difference (HSD) test was used to check for differences between groups. Differences were considered significant where $P<0.05$. Statistical analyses were carried out using Statistica for Windows, version 6.0. 


\section{Results}

\subsection{Seasonal and interannual patterns in POC and FP flux}

The interannual variability and magnitude of the deepwater POC flux was markedly different between P2 and P3 (Fig. 3a). At P3, there was a double seasonal peak, with a primary higher peak occurring in November-December and a secondary lower peak in March-April each year. POC flux at $\mathrm{P} 3$ ranged between a maximum of 22.91 and a minimum of $0.54 \mathrm{mg} \mathrm{C} \mathrm{m}^{-2} \mathrm{~d}^{-1}$. At P2, seasonal oscillations in POC flux were less evident and the maximum POC flux was 1 order of magnitude lower than that observed at P3. Maximum and minimum fluxes at $\mathrm{P} 2$ were 4.01 and $0.43 \mathrm{mg} \mathrm{C} \mathrm{m}^{-2} \mathrm{~d}^{-1}$ respectively.

The differences between the two sites were also reflected in the FP and FPC flux (Fig. 3b, c). While the seasonal range in FP flux varied between 56 and $2534 \mathrm{FP} \mathrm{m}^{-2} \mathrm{~d}^{-1}$ at P3, the range was almost 3 times smaller at $\mathrm{P} 2$, with minimum and maximum values of 36 and $915 \mathrm{FP} \mathrm{m}^{-2} \mathrm{~d}^{-1}$ respectively. FPC flux varied between 0.24 and $11.32 \mathrm{mg} \mathrm{C} \mathrm{m}^{-2} \mathrm{~d}^{-1}$ at P3, with the peak being 1 order of magnitude smaller at $\mathrm{P} 2$ and ranging between 0.20 and $1.3 \mathrm{mg} \mathrm{C} \mathrm{m}^{-2} \mathrm{~d}^{-1}$.

At P3, the seasonal trajectory in FP and FPC flux matched that of the POC flux, with a high peak in late spring-summer, a lower peak in late summer-early autumn and a minimum FP flux during the winter period (May to August). Like total POC, such seasonal peaks and troughs were less evident at $\mathrm{P} 2$.

The dominance of the different FP categories also showed notable differences between the two stations (Fig. 4). The relative dominance of different FP types varied over the course of the year at P3, with ovoidal (small copepod and pteropod) and cylindrical (krill and large copepod) FPs making up around $70 \%$ of the assemblage. Tabular (salp) FPs became most prominent during the autumn-winter season, when they made up $12 \%$ of the total number of FPs. The FP assemblage at P2 was comparatively more homogeneous, with ovoidal (small copepod and pteropod) FPs making up more than $60 \%$ of the FP assemblage across all years and seasons. Round (small copepod and amphipod), cylindrical (krill and large copepod) and ellipsoidal (larvacean) FPs contributed a maximum of 33, 19 and 5\% respectively of all FPs at P2. In general, at P3, all the FP types were consistently present all year round, while they were absent at different times at P2.

\subsection{FP characteristics}

The characteristics of the FP types themselves also varied between sites and seasons. At P3, ovoidal FPs were relatively large and often dark brown in appearance. Ovoidal FPs at P2, by contrast, were often smaller in size and a lighter, yellowbrown colour. SEM investigations found that FPs at P3 were always well-compacted and intact with only a small propor- tion with evident signs of degradation $(<35 \%)$. At P2, except for ovoidal FPs $(<10 \%)$, up to $70 \%$ of each pellet category was degraded, with the peritrophic membrane broken in some places and FPs often fragmented (Fig. 5a). The amount of "fluff" (significantly degraded and therefore unrecognizable remnants of FPs) was higher at P2 than at P3.

During late spring and early summer at P3, $91 \%$ of FP contained well-preserved centric and pennate diatoms. Diatoms were also present in FPs collected in late summerautumn, although in the majority of FPs $(70 \%)$, they were present as small fragments (Fig. 5b). Throughout the year at P2, FPs (>54\%) mainly contained reworked biogenic detritus (most likely, the remains of diatoms and organic material). At both locations, autumn FPs also contained silicoflagellates mixed within an organic matrix.

\subsection{FPC contribution to POC flux}

FPC content varied between the seasons and categories (Table 1). In general, FPC values were at their lowest during the autumn-winter period at both sites.

At P3, significant relationships were found between total POC flux and either FPn or \%FPC, with the best fit between POC flux and FPn being a positive linear relationship $(F=6.21, \mathrm{DFt}=34, P=0.018)$ and a negative linear relationship between POC and \%FPC $(F=48.85, \mathrm{DFt}=34$, $P<0.0001$, Fig. 6 upper). No significant relationships were found between POC and either FPn or \%FPC at P2 (Fig. 6 lower).

\% FPC was significantly higher at $\mathrm{P} 3$ than at $\mathrm{P} 2$ throughout the year (ANOVA, $F=13.32$, Dft $=29.2$, Tukey HSD $p<0.001$ ). Over the course of the year at P3, \% FPC was significantly lower during spring than in summer and autumn-winter (ANOVA, DFt $=4.21, F=7.03$, Tukey HSD $p<0.005$, Fig. 7a). \%FPC did not vary significantly over the course of the year at $\mathrm{P} 2(p=0.321$, Fig. 7b).

At P3, the ovoidal (small copepods and amphipods) and cylindrical (krill and large copepods) categories made the largest contribution to \% FPC amongst all FP categories. The exception was during spring, when the relative contributions were more evenly split between FP categories. It was also notable that tabular (salps) FPs contributed around $20 \%$ to $\%$ FPC during autumn-winter but were only minor contributors in spring and summer. At P2, the majority of \%FPC was made up by ovoidal (small copepods and amphipods) FPs throughout the year.

\section{Discussion}

\subsection{C export downstream and upstream of South Georgia}

The phytoplankton bloom downstream of South Georgia is a relatively consistent feature that is most likely a result of the continual resupply of nutrients and iron from shelf- 


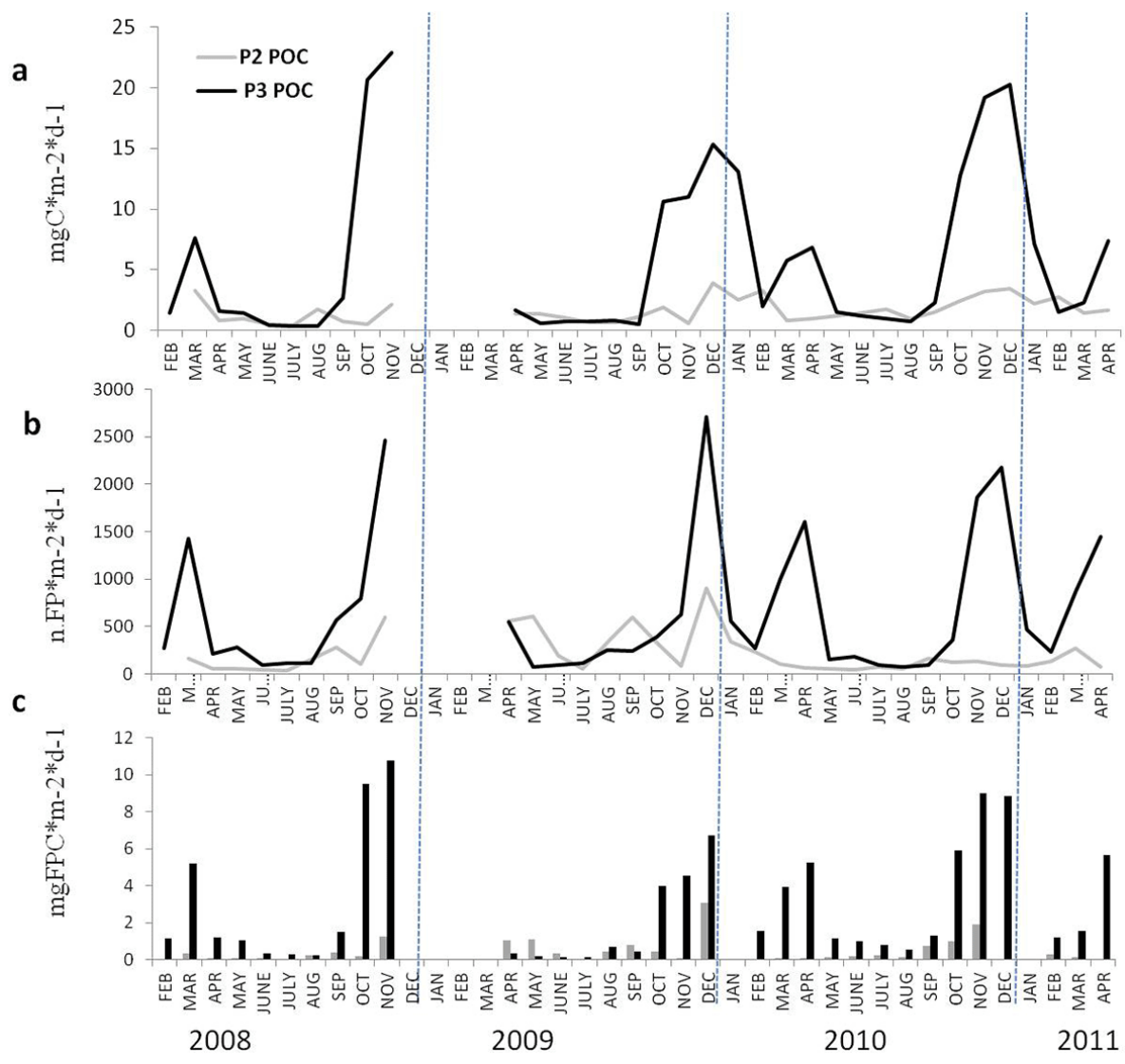

Figure 3. Interannual variability (2008-2011) of (a) POC $\left(\mathrm{mg} \mathrm{C} \mathrm{m}^{-2} \mathrm{~d}^{-1}\right.$ ), (b) FP (n. FP m${ }^{-2} \mathrm{~d}^{-1}$ ), (c) FPC $\left(\mathrm{mg} \mathrm{FPC} \mathrm{m}^{-2} \mathrm{~d}^{-1}\right)$ at P3 (black) and P2 (grey).

Table 1. Average FPC $\left( \pm \mathrm{SD}, \mathrm{mg} \mathrm{C} \mathrm{mm}{ }^{-3}\right)$ of each FP category in spring-early autumn and autumn-winter.

\begin{tabular}{lrrrr}
\hline & Ovoid and ellip. & Round & Cylind. & Tabular \\
\hline Spring-early autumn & $0.052 \pm 0.005$ & $0.035 \pm 0.004$ & $0.030 \pm 0.006$ & $0.045 \pm 0.015$ \\
Autumn-winter & $0.034 \pm 0.006$ & $0.027 \pm 0.008$ & $0.018 \pm 0.006$ & $0.028 \pm 0.012$ \\
\hline
\end{tabular}

influenced waters, akin to the situations found in the Kerguelen and Crozet regions (Pollard et al., 2009). This study found that POC export at the site downstream of South Georgia (P3) was at least 1 order of magnitude greater than the flux at the less productive upstream site (P2). Conversely, the relatively low POC flux at P2, which is upstream of South Georgia and does not receive shelf-influenced nutrientenhanced waters, reflects the low levels of productivity found there (Korb et al., 2008; Borrione and Schlitzer, 2013). The comparison of these two contrasting sites illustrates that enhanced productivity augments levels of carbon export to the deep ocean. By contrast, Buessler (1998) compared production in the surface layers to export to depth in a wide range of ocean settings and seasons and contended that much of the ocean is characterized by low POC export relative to primary production. Our present results agree with Pollard et al. (2007) and Blain et al. (2007), who proposed that POC flux at sites naturally fertilized by iron can be substantial compared to the larger part of the Southern Ocean where iron remains limited. These iron-fertilized sites, although relatively small in area, make a substantial contribution to the biological carbon pump in the Southern Ocean (Blain et al., 2007).

A notable pattern in the present study was the double seasonal peak in POC and FP at P3 (Fig. 8), which is the first to be reported in the Southern Ocean. Recently, Borrione and Schlitzer (2013), on the basis of 12 years of sea-surface satellite data, resolved two recurrent annual blooms in the region downstream of South Georgia (a first peak in the spring followed by a second peak during late austral summer or early autumn). The authors attributed the second peak to a renewed supply of silicate, which reaches limiting concen- 


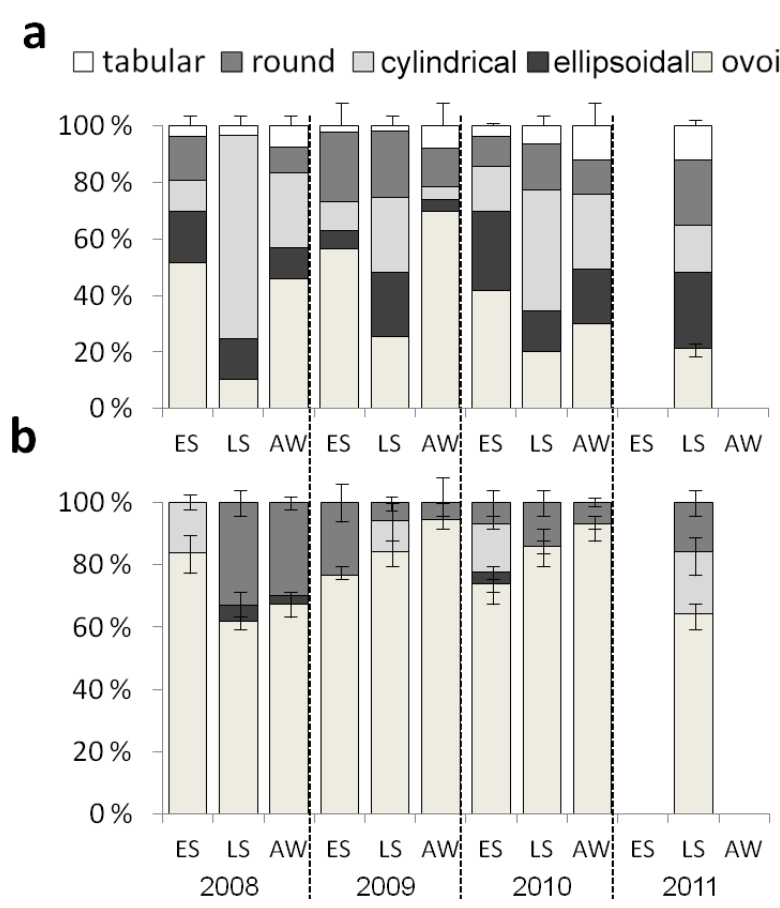

Figure 4. Percentage contribution of different FP types to total FP community between 2008 and 2011 at P3 (upper) and P2 (lower). Data is grouped according to season: ES stands for early season, LS for late season, AW for autumn-winter. Note: cylindrical attributable to krill and large copepods, tabular to salps, ovoidal to small copepods and pteropods, round to small copepods and amphipods, and ellipsoidal to larvaceans. Error bars indicate the standard error of the mean.

trations in January and terminates the first bloom. It follows that the secondary peak is more likely to be dominated by less siliceous microplankton, such as flagellates and forams. This agrees with our findings of greater levels of silicoflagellates in FPs during autumn (see below). Korb et al. (2012) found microplankton to succeed diatoms across transects in the Scotia Sea carried out in spring and then summer.

\subsection{Variability in the assemblage and contents of FPs}

The bimodal seasonal peaks in FP and FPC flux at P3 differed not only in their magnitude but also in the assemblage of FPs they contained. In the spring, intact diatoms were densely packed in the FPs while, in the late summer, FPs were less dense and characterized by more highly fractured diatoms, organic matrix and silico- and dinoflagellates. This suggests that FP producers shifted from a herbivorous to an omnivorous diet over the course of the season. By last autumn-winter, the FPs became whiter in colour. Urban-Rich et al. (1998) considered similar looking FPs to characterize a detritivorous diet combined with a greater consumption of flagellates.

The differences in FP content and flux intensity between the primary and secondary FP and FPC seasonal peaks at
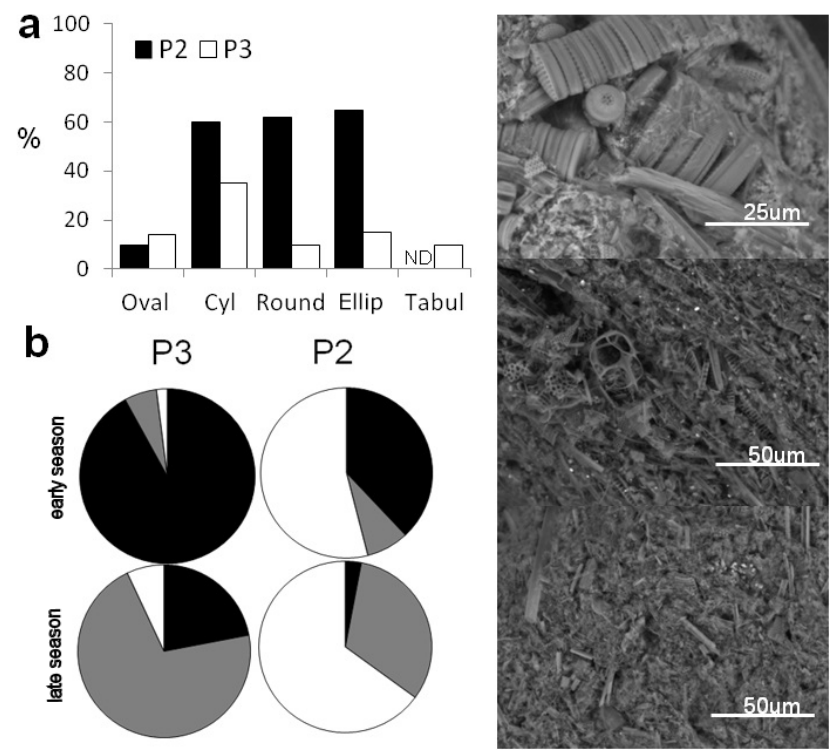

Figure 5. Left: (a) percentage of FP with evidence of degradation (i.e fragmented and/or with the peritrophic membrane partially broken) at P3 and P2; (b) percentage of FP within sediment trap samples from early season (upper) and late season (lower) at P3 and P2, presenting mainly a content of intact diatoms (grey), fragmented diatoms (black) and reworked material (white). Right: scanning electron micrographs showing the diversity of FPs within sediment trap material.

P3 reflect the likely composition of the phytoplankton community between these two periods. Korb et al. (2012) reported early summer blooms in this region to be dominated by heavily silicified diatoms, such as Chaetoceros pennatum, while more weakly silicified diatoms such as Thalassionema nitzschoides predominated in the late summer, to be succeeded by heterotrophic dinoflagellates in the autumn. The consumption of these different food types will in turn influence the sinking speed of the resulting FPs. In early summer, the FPs are likely to sink faster since they contain heavy diatoms, while, later in the year, sinking speeds will be slower as the FPs will more likely contain less-silicified diatoms and heterotrophs.

At P2, by contrast, there is an absence of FPs containing well-packed and intact diatoms with the majority containing a mix of degraded diatoms, organic matrix and detritus. Compared to P3, where there is a clear shift in FP type and content with season, the nature of FPs at P2 reflects a stable zooplankton community with a consistent diet throughout the year. The P2 site is characterized by short blooms of T. nitzschoides and Pseudonitzschia lineola followed by microbial food webs (Korb et al., 2008) that favour remineralization processes such as coprophagy and coprohexy, similar to those reported by (Gonzales et al., 2004) in unproductive areas of the South-east Pacific. Evidence for coprophagy and coprohexy is reflected in the increasing number of fragmented FPs collected at P2. In agreement with this finding, 

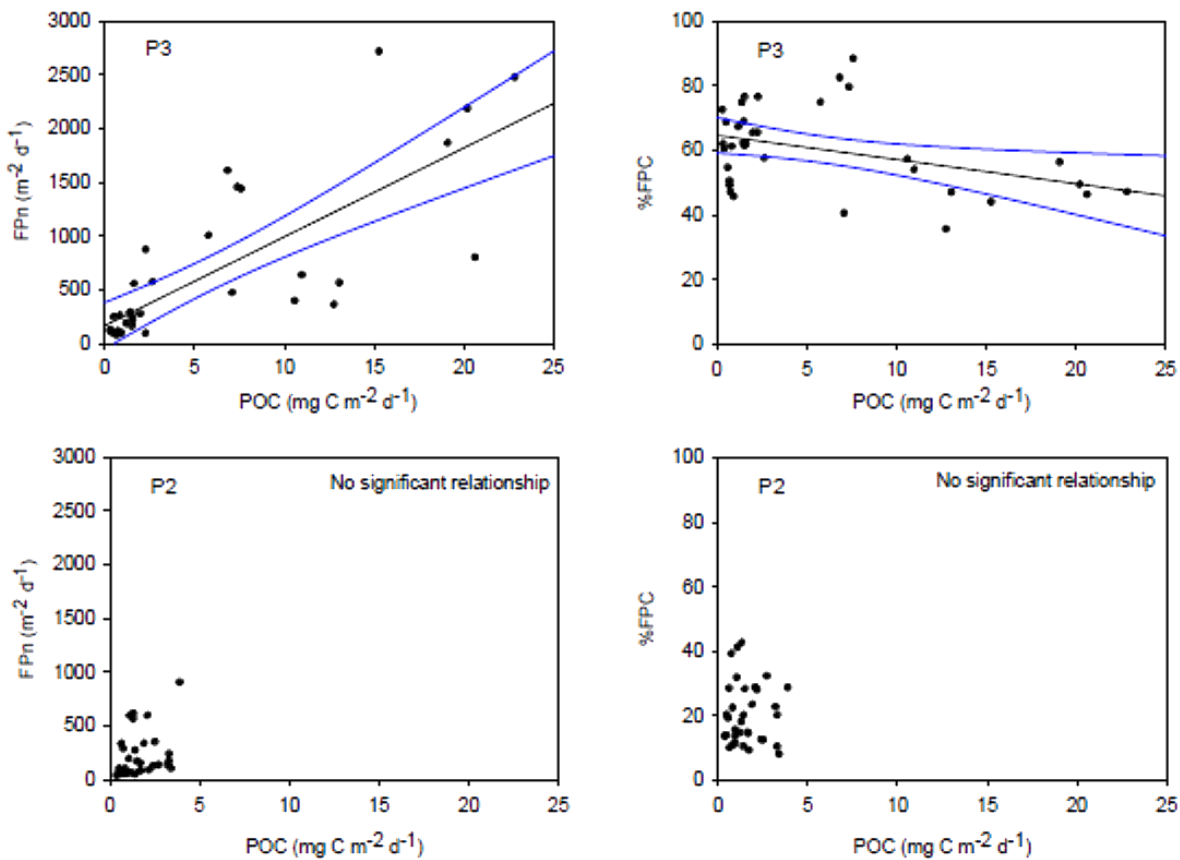

Figure 6. Relationship between POC $\left(\mathrm{mg} \mathrm{C} \mathrm{m}^{-2} \mathrm{~d}^{-1}\right)$ and $\mathrm{FPn}\left(\mathrm{m}^{-2} \mathrm{~d}^{-1}\right.$, left), on the one hand, and \%FPC (right), on the other hand, for $\mathrm{P} 2$ and P3. Solid lines show fitted regressions with $95 \%$ confidence intervals.

abundances of Oithona and cyclopoid nauplii, which commonly recycle material, were greater at $\mathrm{P} 2$ than at $\mathrm{P} 3$ (Ward et al., 2012).Thus, characterizing the assemblages and contents of FPs at the P3 and P2 sites has proved to be an effective means of defining their respective resident zooplankton communities and dominant feeding modes (i.e. an ephemeral phytoplankton-grazing community in the former, a more stable, coprophagous community in the latter). This in turn has allowed certain inferences to be made with regard to the potential for FP export at the two sites. Early season FPs at P3 contain tightly packed, heavily silicified diatoms with rapid sinking speeds and a high likelihood of export. By contrast, even when FPs are produced at P2, their lower densities increase their residence time in the upper layers, resulting in a greater likelihood of interception and being broken up.

An interesting further feature at P3 was the recurrence of salps (tabular) FPs each autumn and winter. Although salps may not be a dominant contributor to biomass in the Scotia Sea region (Ward et al., 2012), they may make a disproportionate contribution to FP flux due to their large, fast-sinking pellets (Anderson, 1998). The fact that the FPs became a major contributor outside of the summer productive period indicates that they must be effective at processing and repackaging heterotrophs and suspended organic matter during the autumn and winter months. Furthermore, it is known that the main salp species, $S$. thompsoni, enters a solitary phase during the winter months, when it descends to depths of around $1000 \mathrm{~m}$ (Loeb and Santora, 2012). Therefore, the FPs found at this time of year are most likely to have been generated deep in the water column from material suspended in the mesopelagic layers.

\subsection{Role of vertical migration and bathypelagic zooplankton in FP export}

A particular difference between $\mathrm{P} 3$ and $\mathrm{P} 2$ was in the comparative degradation state of the FPs. At P3, we found that FPs in both the primary and secondary peak fluxes were in a relatively intact state. This contrasts with the P2 site, where FPs were less intact, with peritrophic membranes broken and cylindrical (krill, large copepods) FPs often fragmented. We highlighted (see previous paragraph) that, due to their content, FPs at P3 can sink faster than at P2 (reducing the exposition time to the degradation process). Nevertheless, we believe that the sinking speed alone may not explain the high number of well-preserved FPs observed at P3 at $2000 \mathrm{~m}$. In fact, FP flux in this study measured in the iron-fertilized region is the highest reported for the Southern Ocean and comparable to FP flux measured in the high-productivity area of Terra Nova Bay polynya in the Ross Sea (Accornero et al., 2003).

We propose that a major factor causing this difference in FP degradation state between the two sites was the extent of diel vertical migration (DVM) in the respective zooplankton communities. Zooplankton DVM can influence mesopelagic carbon flux substantially by increasing the depth at which FPs are released into the system (Buesseler and Boyd, 2009; Wallace et al., 2013). Mineralization processes, further up the water column, are bypassed and FPs can sink relatively 


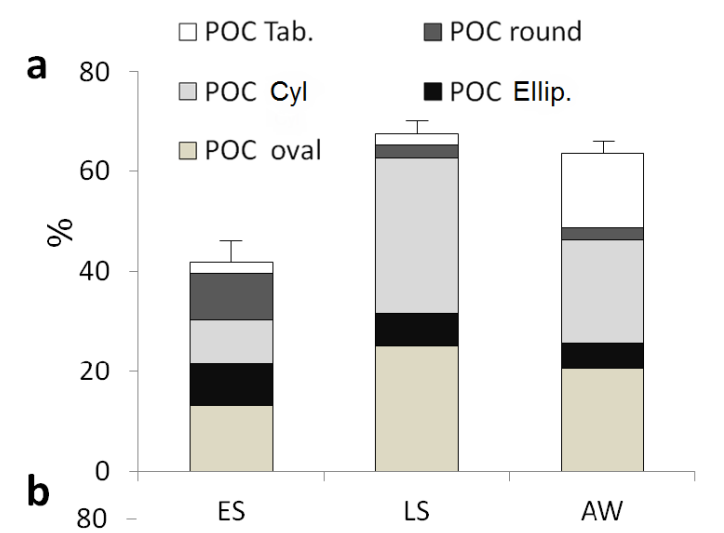

60

¿ 40

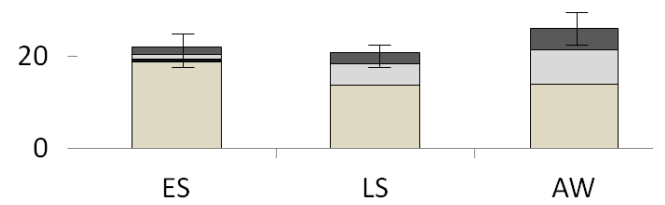

Figure 7. \%FPC to total POC of each FP types during early season (ES), late season (LS) and autumn-winter (AW) at P3 (upper) and P2 (lower). Values were averaged over the period 2008-2011. Note: cylindrical attributable to krill and large copepods, tabular to salps, ovoidal to small copepods and pteropods, round to small copepods and amphipods, and ellipsoidal to larvaceans. Error bars indicate the standard error of the mean.

intact to the deep ocean. Indeed, such an active movement of FPs to deeper ocean layers can occur even in the absence of synchronized DVM, as occurs during periods of midnight sun (Wallace et al., 2013). We propose that DVM and/or unsynchronised VM (vertical migration) is a more prominent feature of the zooplankton community residing at the $\mathrm{P} 3$ site.

At the P2 site, ovoidal FPs (small copepods and/or pteropods) dominated and contained large amounts of reworked material. These FPs were less dense than ovoidal FPs at the P3 site and so were unlikely to have had a rapid transit to depth. A more likely scenario is that the organisms (most likely copepods) that generated the FPs resided well below the mixed layer, where they consumed detrital matter and repackaged it into FPs. The generation of FPs by detritivores fits with the further observation of this FP type being present at a relatively constant level year-round at the P2 site. The release of the FPs in the deeper layers can explain why they were in a much more intact state compared to other FP types, probably generated closer to the surface. It is known that zooplankton residing within the deeper layers of the ocean consume FPs, break them apart and repackage them several times over the course of their descent (Conte et al., 2001). The important role of deep-dwelling zooplankton in the re-
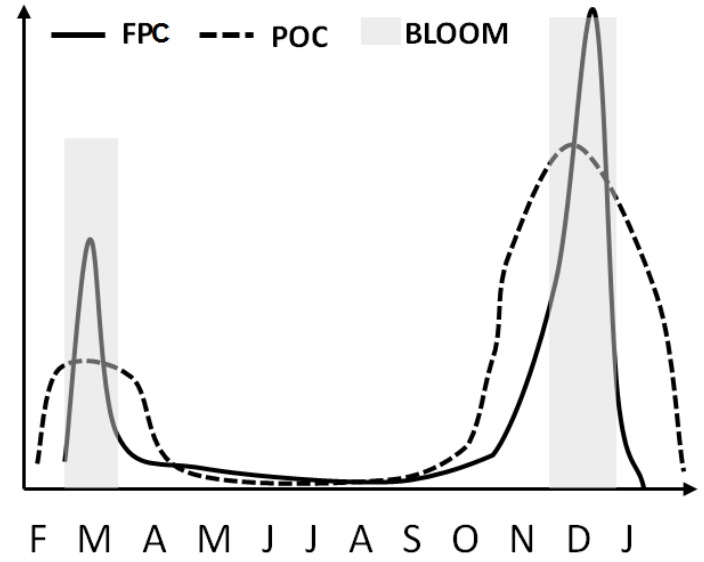

Figure 8. Schematic diagram representing the recurrent trend of POC and FPC flux (from 2008 to 2011) in relation to the bloom periods at the $\mathrm{P} 3$ site.

cycling and reprocessing of FPs at the P2 site is in line with a number of others studies that have considered the role of the bathypelagic zooplankton community in the downward flux of material (Pilskaln and Honjo, 1987; Gonzalez et al., 2000; Wilson et al., 2013). Despite the likelihood that the largest part of deep-dwelling zooplankton might not have been "captured" by sediment traps, a relatively high number of swimmers were observed at $\mathrm{P} 2$, while at $\mathrm{P} 3$ their abundance was extremely low (fewer than organisms per sample).

\subsection{FP contribution to the deep-carbon transfer}

The present study made direct measurements of FPC for each FP category. Many FP flux studies have considered this value to be constant over time, but our results indicated that its variability may be considerable between seasons, with FPC being up to $40 \%$ lower in the autumn-winter season compared to spring-summer. This is in agreement with FP production experiments by Urban-Rich et al. (1998) and Atkinson et al. (2012), who found this ratio to vary with food availability. Our results highlight the importance of directly measuring FPC content when estimating parameters such as \%FPC and its relationship to POC flux over annual cycles.

We found maximum \% FPC values to be 91 at $\mathrm{P} 3$ and $42 \%$ at $\mathrm{P} 2$. Both of these values are in the upper range of those reported for other sites at similar depths (Table 2). Similar values of \%FPC presented in this study were observed only in the highly productive upwelling regions off the west coasts of South America (Gonzales et al., 2004) and California (Wilson et al., 2013). Our results highlight that, in the Scotia Sea region, zooplankton and their FPs have an important role in determining the level of $\mathrm{C}$ export. This is in line with several studies that found extremely high levels of zooplankton biomass in the Scotia Sea compared to the rest of the Southern Ocean (Ward and Shreeve, 1995; Atkinson, 1996; Pakhomov et al., 1997). 
Table 2. Literature survey of maximum \%FPC to total POC in sediment trap material. Note: S stands for summer, LS for late summer, A for autumn, Sp for spring and W for winter; SG stands for South Georgia.

\begin{tabular}{lrrll}
\hline Location & $\begin{array}{r}\text { Sediment Trap } \\
\text { Depth (m) }\end{array}$ & $\begin{array}{r}\text { Max FPC } \\
(\%)\end{array}$ & Season & Study \\
\hline SG (P3) & 2000 & 91 & LS & This study \\
SG (P2) & 1500 & 43 & LS & This study \\
Monterey & 1500 & 4 & A & Urrere and Knauer (1981) \\
Mediterranean & 2300 & 35 & W & Caroll et al. (1998) \\
Southern Ocean & $1200-2700$ & 4 & S & Suzuki et al. (2001) \\
Creta Sea & 1500 & 6 & Sp & Wasmann et al. (2000) \\
Coquimbo, Chile & 2300 & 98 & S-A & Gonzales et al. (2004) \\
Sargasso Sea & 1500 & 16 & S & Shatowa et al. (2012) \\
North-east Pacific & 3500 & 62 & S-A & Wilson et al. (2013) \\
\hline
\end{tabular}

We found there to be a significant negative relationship between \%FPC and POC at the P3 site. In effect, this relationship demonstrates that FPs make a proportionally greater contribution to total carbon flux when POC levels are comparatively low. Conversely the positive relationship between FPn and POC flux that we observed does not take account of FP size and content and may reflect the presence of a large contribution from smaller, early developmental zooplankton stages that are only minor contributors to FPC. Wilson al. (2013) also found a negative relationship between \%FPC and POC and went on to suggest that this may be a common feature of deep-sea fluxes. The negative relationship between $\%$ FPC and POC flux at P3 could be a consequence of several processes. Firstly, primary production has exceeded zooplankton consumption during the bloom phase, leading to the mass sinking of the ungrazed fraction at the point of bloom collapse. Observations in our sediment trap samples of a considerable quantity of phytodetritus during this period support this finding. Secondly, in this period, we also observed increased levels of zooplankton moults and carcasses in the traps, which contributed to POC flux and in turn increase the inverse relationship between \%FPC and POC. Thirdly, production and consumption were not in phase at that time, meaning that there was a temporal decoupling between the bloom period and the establishment of a grazer community. Finally, the difference in relative sinking speeds of FPs and slow sinking phytodetritus ( $<150 \mathrm{~m} \mathrm{~d}^{-1}$; Billet et al., 1983) and the relatively low resolution of the sediment traps (1530 days) may contribute to obscuring a more complex temporal relationship between \%FPC and POC. The identification and quantification of the phytoplankton community in the sediment trap samples will be a priority in future investigations.

There was no relationship between POC flux and either \%FPC or FPn at P2. This highlights that, in areas of relatively low productivity, FPs are reworked by the zooplankton community through processes such as coprophagy and coprohexy. FPC flux is therefore altered through the partial loss and degradation of some FPs.
More broadly, our results highlight that the zooplankton community type and its feeding mode can have a controlling influence on the quantity and quality of carbon exported to the ocean interior. In the two contrasting sites that typify wider-scale situations within the Southern Ocean the magnitude of carbon export to the deep ocean altered according to the different zooplankton communities and their generation and reworking of FPs. Imbalances between organic carbon sources and sinks is a common issue within models of global carbon export (Lutz et al., 2007; Dunne et al., 2007; Schlitzer, 2004; Henson et al., 2011). This imbalance indicates either the existence of unaccounted for sources of organic carbon or that metabolic activity in the deep ocean is being overestimated (Burd et al., 2010). In this study, we demonstrate that plankton community structure (and zooplankton behaviour) can significantly influence the level of $\mathrm{C}$ flux and must be included within global $\mathrm{C}$ export models.

Acknowledgements. We thank D. Pond and the captains and crew of the RRS James Clark Ross for their support in the deployment and recovery of sediment traps. E. Murphy, J. Watkins, R. Korb and $\mathrm{M}$. Whitehouse helped in the initial strategic design of the moorings and their locations. P. Ward and S. Thorpe provided invaluable advice on the interpretation of our results. P. Geissler carried out the $\mathrm{CHN}$ analysis. We thank A. Belcher for providing Fig. 1. Furthermore, we thank L. Langone and the anonymous reviewer for their helpful comments that improved the initial manuscript. This work was carried out as part of the Ecosystems programme at the British Antarctic Survey.

Edited by: G. Herndl

\section{References}

Accornero, A., Manno, C., Esposito, F., and Gambi, C.: The vertical flux of particulate matter in the polynya of Terra Nova Bay: results from moored sediment traps (1995-1997). Part II biological components, Antarct. Sci., 15, 175-188, 2003. 
Anderson, V. and Nival, P.: A pelagic ecosystem model stimulating production and sedimentation of biogenic particles: role of salps and copepods, Mar. Ecol. Prog. Ser., 44, 35-50, 1988.

Atkinson, A.: Subantarctic copepods in an oceanic, low chlorophyll environment: ciliate predation, food selectivity and impact on prey populations, Mar. Ecol. Prog. Ser., 130, 85-96, 1996.

Atkinson, A., Whitehouse, M. J., Priddle, J., Cripps, G. C., Ward P., and Brandon, M. A.: South Georgia, Antarctica: a productive, cold water, pelagic ecosystem, Mar. Ecol. Prog. Ser., 216, 279308,2001

Atkinson, A., Schmidt, K., Fielding, S., Kawaguchi, S., and Geissler, P.: Variable food absorption by Antarctic krill: relationships between diet, egestion rate and the composition and sinking rates of their fecal pellets, Deep-Sea Res. II, 59-60, 147-158, 2012.

Baer Jones, K. N.: Characterising the biological uptake of $\mathrm{CO}_{2}$ across the Subtropical Frontal Zone (Thesis, Doctor of Philosophy), University of Otago, available at: http://hdl.handle.net/ 10523/2355, 2012.

Bathmann, U. and Liebezeit, G.: Chlorphyll in copepod faecal pellets: changes in pellet numbers and pigment content during a declining Baltic spring bloom, Pubbl. Staz. Zool. Napoli (I: Mar. Ecol.), 7, 59-73, 1986.

Billett, D. S. M., Lampitt, R. S., Rice, A. L., and Mantoura, R. F. C.: Seasonal sedimentation of phytoplankton to deep-sea benthos, Nature, 302, 520-522, 1983.

Blain, S., Quéguiner, B., Armand, L., Belviso, S., Bombled, B., Bopp, L., Bowie, A., Brunet, C., Brussaard, K., Carlotti, F., Christaki, U., Corbière, A., Durand, I., Ebersbach, F., Fuda, J. L., Garcia, N., Gerringa, L. J. A., Griths, F. B., Guigue, C., Guillerm, C., Jacquet, S., Jeandel, C., Laan, P., Lefèvre, D., Lomonaco, C., Malits, A., Mosseri, J., Obernosterer, I., Park, Y. H., Picheral, M., Pondaven, P., Remenyi, T., Sandroni, V., Sarthou, G., Savoye, N., Scouarnec, L., Souhault, M., Thuillers, D., Timmermans, K. R., Trull, T., Uitz, J., Van-Beek, P., Veldhuis, M. J. W., Vincent, D., Viollier, E., Vong, L., and Wagener, T.: Effect of natural iron fertilization on carbon sequestration in the Southern Ocean, Nature, 446, 1070-1075, 2007.

Borrione, I. and Schlitzer, R.: Distribution and recurrence of phytoplankton blooms around South Georgia, Southern Ocean, Biogeosciences, 10, 217-231, doi:10.5194/bg-10-217-2013, 2013.

Bruland, K. W. and Silver, M. W.: Sinking rates of faecal pellets from gelatinous zooplankton (salps, pteropods, doliolids), Mar. Biol., 63, 295-300, 1981.

Buesseler, K. O.: The decoupling of production and particulate export in the surface ocean, Global Biogeochem. Cy., 12, 297-310, doi:10.1029/97GB03366, 1998.

Buesseler, K. O. and Boyd, P. W.: Shedding light on processes that control particle export and flux attenuation in the twilight zone of the open ocean, Limnol. Oceanogr. 54, 1210-1232, 2009.

Burd, A. B., Hansell, D. A., Steinberg, D. K., Anderson, T. R., Arístegui, J., Baltar, F., Beaupré, S. R., Buesseler, K. O., DeHairs, F., Jackson, G. A., Kadko, D. C., Koppelmann, R., Lampitt, R. S., Nagata, T., Reinthaler, T., Robinson, C., Robison, B. H., Tamburini, C., and Tanaka, T.: Assessing the apparent imbalance between geochemical and biochemical indicators of meso- and bathypelagic biological activity: what the @\$\#! is wrong with present calculations of carbon budgets?, Deep-Sea Res. II, 57, 1557-1571, 2010.
Carroll, M. L., Miquel, J.-C., and Fowler, S. W.: Seasonal patterns and depth-specific trends of zooplankton fecal pellet fluxes in the Northwestern Mediterranean Sea, Deep-Sea Res. I, 45, 1303 1318, 1998.

Conte, M., Ralph, N., and Ross, E.: Seasonal and interannual variability in deep ocean particle fluxes at the Oceanic Flux Program (OFP)/Bermuda Atlantic Time Series (BATS) site in the western Sargasso Sea near Bermuda, Deep-Sea Res. II, 48, 1471-1505, doi:10.1016/S0967-0645(00)00150-8, 2001.

Dagg, M. J., Urban-Rich, J., and Peterson, J. O.: The potential contribution of faecal pellets from large copepods to the flux of biogenic silica and particulate organic carbon in the Antarctic Polar Front region near 1701W, Deep-Sea Res. II, 50, 675-691, 2003.

Dunne, J. P., Sarmiento, J. L., and Gnanadesikanm, A.: A synthesis of global particle export from the surface ocean and cycling through the ocean interior and on the seafloor, Global Biogeochem. Cy., 21, GB4006, doi:10.1029/2006GB002907, 2007.

Fischer, G., Futterer, D., Gersonde, R., Honjo, S., Ostermann, D., and Wefer, G.: Seasonal variability of particle flux in the Weddell Sea and its relation to ice cover, Nature, 335, 426-428, 1988.

Fowler, S. W. and Kanuer, G. A.: Role of large particles in the transport of elements and organic compounds through the oceanic water column, Prog. Oceanogr., 16, 147-194, doi:10.1016/00796611(86)90032-7, 1986.

Fowler, S. W., Small, L. F., and LaRosa, J.: Seasonal particulate carbon flux in the coastal northwestern Mediterranean Sea, and the role of zooplankton faecal matter, Oceanol. Acta., 14, 77-86, 1991.

Gonzalez, H. E.: The distribution and abundance of krill faecal material and oval pellets in the Scotia and Weddell seas (Antarctica) and their role in particle flux, Polar Biol., 12, 81-91, 1992.

Gonzalez, H. E. and Smetacek, V.: The possible role of the cyclopoid copepod Oithona in retarding vertical flux of zooplankton fecal material, Marine Ecol.-Prog. Ser., 113, 233-246, 1994.

Gonzalez, H. E., Ortiz, V. C., and Sobrazo, M.: The role of the faecal material in the particulate organic matter flux in the northern Humbolt Current, Chile (230 S), before and during the 19971998 El Nino, J. Plankton Res., 22, 499-529, 2000.

Gonzalez, H. E., Hebbeln, D., Iriarte, J. L., and Marchant, M.: Downward fluxes of faecal material and microplankton at $2300 \mathrm{~m}$ depth in the oceanic area off Coquimbo (30 degrees S), Chile, during 1993-1995, Deep-Sea Res. II, 51, 2457-2474, 2004.

Gorsky, G. and Fenaux, R.: The role of appendicularia in marine food webs, in: The biology of pelagic tunicates, edited by: Bone, Q., 159-169, Oxford Univ. Press, 1998.

Henson, S. A., Sanders, R., Madsen, E., Morris, P. J., Le Moigne, F., and Quartly, G. D.: A reduced estimate of the strength of the ocean's biological carbon pump, Geophys. Res. Lett., 38, L04606, doi:10.1029/2011GL046735, 2011.

Kobari, T., Steinberg, D. K., Ueda, A., Tsuda, A., Silver, M. W., and Kitamura, M.: Impacts of ontogenetically migrating copepods on downward carbon flux in the western subarctic Pacific Ocean, Deep-Sea Res. II, 55, 1648-1660, 2008.

Komar, P. D., Morse, A. P., Small, L. E., and Fowler, D.: An analysis of sinking rates of natural copepods and euphausiid faecal pellets, Limnol. Oceanogr., 26, 172-180, 1981.

Korb, R. E., Whitehouse, M. J., Atkinson, A., and Thorpe, S. E.: Magnitude and maintenance of the phytoplankton bloom at 
South Georgia: a naturally iron-replete environment, Mar. Ecol.Prog. Ser., 368, 75-91, doi:10.3354/meps07525, 2008.

Korb, R. E., Whitehouse, M. J., Ward, P., Gordon, M., Venables, H. J., and Poulton, A. J.: Regional and seasonal differences in microplankton biomass, productivity, and structure across the Scotia Sea: Implications for the export of biogenic carbon, Deep-Sea Res. II, 59-60, 67-77, doi:10.1016/j.dsr2.2011.06.006, 2012.

Lampitt, R. S., Noji, T. T., and Von Bodungen, B.: What happens to zooplankton faecal pellets? Implications for material flux, Mar. Biol., 104, 15-23, doi:10.1007/BF01313152, 1990.

Loeb, V. J. and Santora, J.: Population dynamics of Salpa thompsoninear the antarctic Peninsula: growth rates and interannual variations in reproductive activity (1993-2009), Prog. Oceanogr., 96, 93-107, 2012.

Lutz, M. J., Caldeira, K., Dunbar, R. B., and Behrenfeld, M. J.: Seasonal rhythms of net primary production and particulate organic carbon flux to depth describe the efficiency of biological pump in the global ocean, J. Geophys. Res., 112, C10011, doi:10.1029/2006JC003706, 2007.

Manno, C., Tirelli, V. , Accornero, A., and Fonda Umani, S.: Importance of the contribution of Limacina helicina faecal pellets to the carbon pump in Terra Nova Bay (Antarctica), J. Plankton Res., 34, 145-152, 2010.

Martin, J. H., Coale, K. H., and Johnson, K. S.: Testing the iron hypothesis in ecosystems of the equatorial Pacific Ocean, Nature, 371, 123-129, 1994.

Pakhomov, E. A., Verheye, H. M., Atkinson, A., Laubscher, R. K., and Taunton-Clark, J.: Structure and grazing impact of the mesozooplankton community during late summer 1994 near South Georgia, Antarctica, Polar Biol., 18, 180-192, 1997.

Pilskaln, C. H. and Honjo, S.: The fecal pellet fraction of biogeochemical particle fluxes to the deep sea, Global Biogeochem. Cy., 1, 31-43, doi:10.1029/GB001i001p00031, 1987.

Pollard, R. T., Salter, I., Sanders, R. J., Lucas, M. I., Moore, C. M., Mills, R. A., Statham, P. J., Allen, J. T., Baker, A. R., Bakker, D. C., Charette, M. A., Fielding, S., Fones, G. R., French, M., Hickman, A. E., Holland, R. J., Hughes, J. A., Jickells, T. D., Lampitt, R. S., Morris, P. J., Nédélec, F. H., Nielsdóttir, M., Planquette, H., Popova, E. E., Poulton, A. J., Read, J. F., Seeyave, S., Smith, T., Stinchcombe, M., Taylor, S., Thomalla, S., Venables, H. J., Williamson, R., and Zubkov, M. V.: Southern Ocean deep-water carbon export enhanced by natural iron fertilization, Nature, 457, 577-580, doi:10.1038/nature07716, 2009.

Schlitzer, R.: Carbon export fluxes in the Southern Ocean: results from inverse modeling and comparison with satellite-based estimates, Deep-Sea Res. II, 49, 1623-1644, 2002.

Schlitzer, R.: Export production in the equatorial and North Pacific derived from dissolved oxygen, nutrient and carbon data, J. Oceanogr., 60, 53-62, doi:10.1023/B:JOCE.0000038318.38916.e6, 2004.

Schmidt, K., Atkinson, A., Steigeneberger, S., Fielding, S., Lindsay, M. C. M., Pond, D. W., Tarling, G. A., Klevjer, T. A., Allen, C. S., Nicol, S., and Achterberg, E. P.: Seabed foraging by Antarctic krill: implications for stock assessment, bentho-pelagic coupling, and the vertical transfer of iron, Limnol. Oceanogr., 56, 14111428,2011
Shatowa, O., Koweek, D., Conte, M. H., and Weber, J. C.: Contribution of zooplankton fecal pellets to deep ocean particle flux in the Sargasso Sea assessed using quantitative image analysis, J. Plankton Res., 34, 905-921, 2012.

Suzuki, H., Sasaki, H., and Fukuki. M.: Short-term variability in the flux of rapidly sinking particles in the Antarctic marginal ice zone, Polar Biol., 24, 697-705, 2001.

Toggweiler, J. R., Gnanadesikan, A., Carson, S., Murnane, R., and Sarmiento, J. L.: Representation of the carbon cycle in box modelsand GCMs: 1. Solubility pump, Global Biogeochem. Cy., 17, 1026, doi:10.1029/2001GB001401, 2003.

Turner, J. T.: Zooplankton fecal pellets, marine snow and sinking phyto- plankton blooms, Mar. Ecol. Prog. Ser., 27, 57-102, 2002.

Urban-Rich, J., Hansell, D. A., and Roman, M. R.: Analysis of copepod fecal pellet carbon using a high temperature combustion method, Mar. Ecol. Prog. Ser., 171, 199-208, doi:10.3354/meps171199, 1998.

Urrere, M. A. and Knauer, G. A.: Zooplankton fecal pellet fluxes and vertical transport of particulate organic material in the pelagic environment, J. Plankton Res., 3, 369-387, 1981.

Wallace, M. I., Cottier, F. R., Brierley, A. S., and Tarling, G. A.: Modelling the influence of copepod behaviour on faecal pellet export at high latitudes, Pol. Biol., 3, 579-592, 2013.

Ward, P. and Shreeve, R. S.: Egg production in three species of Antarctic copepod during an austral summer, Deep-Sea Res. I, 42, 721-735, 1995.

Ward, P., Atkinson, A., Venables, H., Tarling, G., Whitehouse, M., Fielding, S., Collins, M., Korb, R., Black, A., Stowasser, G., Schmidt, K., Thorpe, S., and Enderlein, P.: Food web structure and bioregions in the Scotia Sea: a seasonal synthesis, Deep-Sea Res. II, 59-60, 253-266, 2012.

Wassmann, P.: Retention versus export food chains: processes controlling sinking loss from marine pelagic systems, Hydrobiologia, 363, 29-57, 1998.

Wassmann, P., Ypma, J. E., and Tselepides, A.: Vertical flux of faecal pellets and microplankton on the shelf of the oligotrophic Cretan Sea (NE Mediterranean Sea), Prog. Oceanogr., 46, 241258, 2000.

Wefer, G., Fisher, G., and Futterer, D.: Seasonal particle flux in the Bransfield Strait, Antarctica, Deep-Sea Res., 35, 891-898, 1998.

Wexels Riser, C., Wassmann, P., Olli, K., Pasternak, A., and Arashkevich, E.: Seasonal variation in production, retention and export of zooplankton faecal pellets in the marginal ice zone and central Barents Sea, J. Mar. Res., 38, 175-188, 2002.

Whitehouse, M., Atkinson, A., Korb, R., Venables, H., Pond, D., and Gordon, M.: Substantial primary production in the landremote region of the central and northern Scotia Sea, Deep-Sea Res. II, 59-60, 47-56, 2012.

Wilson, S. E., Ruhl, H. A., and Smith, K. L.: Zooplankton faecal pellet flux in the abyssal northeast Pacific: A 15 year time-series study, Limnol. Oceanogr., 58, 881-892, 2013.

Yoon, W. D., Kim, S. K., and Han, K. N.: Morphology and sinking velocities of fecal pellets of copepod, molluscan, euphausiid, and salp taxa in the northeastern tropical Atlantic, Mar. Biol., 139, 923-928, doi:10.1007/s002270100630, 2001. 